\title{
Deglucose chikusetsusaponin IVa isolated from Rhizoma Panacis Majoris induces apoptosis in human HepG2 hepatoma cells
}

\author{
XIAOMEI SONG* ${ }^{*}$ WEI WANG* ${ }^{*}$ XIN ZHANG, YI JIANG, XINJIE YANG, \\ CHONG DENG, ZHENGGANG YUE and ZHISHU TANG
}

\author{
Shaanxi Collaborative Innovation Center of Chinese Medicinal Resource Industrialization, \\ Shaanxi Province Key Laboratory of New Drugs and Chinese Medicine Foundation Research, \\ Shaanxi Rheumatism and Tumor Center of TCM Engineering Technology Research, School of Pharmacy, \\ Shaanxi University of Chinese Medicine, Xianyang, Shaanxi 712046, P.R. China
}

Received September 3, 2014; Accepted May 19, 2015

DOI: $10.3892 / \mathrm{mmr} .2015 .4035$

\begin{abstract}
Deglucose chikusetsusaponin IVa (DCIVa), isolated from Rhizoma Panacis Majoris, a widely used traditional Chinese medicine, is a type of oleanane triterpenoids. Various previous studies have demonstrated that oleanane triterpenoids exhibit cytotoxic activity against various types of cancer cells. However, whether DCIVa exerts an antitumor effect remains to be elucidated. The present study aimed to assess the effect of DCIVa on cancer cells using the HepG2 hepatocellular carcinoma cell line and determine the underlying mechanism. Using an MTT assay, it was demonstrated that DCIVa inhibited cell growth and viability in a dose- and time-dependent manner. Typical apoptotic features, including chromatin condensation and margination at the nuclear periphery, and apoptotic body formation were induced by DCIVa and were detected by transmission electron microscopy. In addition, nuclear condensation and fragmentation were also observed by Hoechst 33258 staining. Furthermore,
\end{abstract}

Correspondence to: Dr Zhishu Tang or Dr Xiaomei Song, Shaanxi Collaborative Innovation Center of Chinese Medicinal Resource Industrialization, Shaanxi Province Key Laboratory of New Drugs and Chinese Medicine Foundation Research, Shaanxi Rheumatism and Tumor Center of TCM Engineering Technology Research, School of Pharmacy, Shaanxi University of Chinese Medicine, Century Avenue, Xianyang, Shaanxi 712046, P.R. China

E-mail: tzs6565@163.com

E-mail: songxiaom@126.com

Abbreviations: DCIVa, deglucose chikusetsusaponin IVa; TCM, traditional Chinese medicine; FBS, fetal bovine serum; MTT, 3-(4,5-dimethylthi-azol-2-yl)-2,5-diphenyltetrazolium bromide; DMSO, dimethyl sulfoxide; PI, propidium iodide; HRP, horseradish peroxidase

\section{*Contributed equally}

Key words: Rhizoma Panacis Majoris, antitumor, deglucose chikusetsusaponin IVa, cytotoxic activity, cell apoptosis, cell cycle arrest flow cytometric analysis revealed that DCIVa increased cell apoptosis and G2/M cell cycle arrest dose-dependently. Western blot analysis further demonstrated that DCIVa upregulated the expression of the pro-apoptotic protein, Bax, and downregulated the expression of the anti-apoptotic protein, Bcl-2. In conclusion, the present study demonstrated for the first time, to the best of our knowledge, that DCIVa exerts potent cytotoxic effects on HepG2 cells through induction of cell apoptosis and cell cycle arrest, and may be utilized as a potential anticancer agent.

\section{Introduction}

Traditional Chinese medicine (TCM), as a complementary and alternative medicine, has been widely used in China for thousands of years (1). From ancient to modern times in China, TCM has been critical in the prevention and treatment of several diseases prior to western medicine being introduced (2). The benefits of TCM are gradually being recognized worldwide, which may aid in the development of novels drugs for the treatment of various types of disease.

Rhizoma Panacis Majoris, also named Zhu Zi Shen or Kou Zi Qi in Chinese, has been widely used for the treatment of several diseases due to its various pharmacological activities. In China, Rhizoma Panacis Majoris is predominantly located in the southwest area, including Shaanxi, Gansu, Ningxia, Henan, Hubei and Yunnan provinces, at an altitude of $1200-4000 \mathrm{~m}$ in the valley of broad-leaved forest (3). Modern chemical investigations have demonstrated that Rhizoma Panacis Majoris predominantly contains saponins, naphtha and organic acids. $(4,5)$. It has been revealed that Rhizoma Panacis Majoris possesses several pharmacological activities. For example, the total saponins of Rhizoma Panacis Majoris have been demonstrated to increase the proliferation of T lymphocytes induced by Sword bean A and Phytohemagglutinin (6). The water extract exhibits anti-inflammatory and analgesic effects in mice (7), and protects the mice against acute cerebral ischemia-reperfusion injury (8). Furthermore, Rhizoma Panacis Majoris was revealed to be capable of reducing the toxicity of chemotherapeutic drugs (9) and exerting an antitumor effect $(10,11)$. 
Deglucose chikusetsusaponin IVa (DCIVa), also termed Oleanolic acid-3-O- $\beta$-D-pyran glucuronic acid glycoside, is also isolated from the extract of Rhizoma Panacis Majoris (12). DCIVa has been revealed to exert an anti-arrhythmic effect (13) and protect against hypoxia/reoxygenation-induced injury in myocardial cells (14). DCIVa is a member of the family of oleanane triterpenoids, which has been reported to have numerous pharmacological activities, including cytotoxic activity against various cancer cells, anti-inflammatory activity, prevention of dental caries and induction of gentamicin nephrotoxicity (15-18). However, whether DCIVa exerts an antitumor effect remains to be elucidated. The present study aimed to investigate the antitumor effect and the underlying mechanism of DCIVa using HepG2 hepatocellular carcinoma cells.

\section{Materials and methods}

Reagents. Fetal bovine serum (FBS) was obtained from Minhai Biotechnology Development (Beijing, China) and RPMI-1640 medium was obtained from Gibco-BRL (Gaithersburg, MD, USA). 3-(4,5-dimethylthi-azol-2-yl)-2,5-diphenyltetrazolium bromide (MTT), dimethyl sulfoxide (DMSO), Hoechst 33258 and propidium iodide (PI) were purchased from Sigma-Aldrich (St. Louis, MO, USA).

Cell culture. The HepG2 hepatocellular carcinoma cells were obtained from The Fourth Military Medical University (Xian, China). The cells were cultured in RPMI-1640 medium supplemented with $10 \%$ FBS, containing $100 \mu \mathrm{g} / \mathrm{ml}$ streptomycin, $100 \mathrm{U} / \mathrm{ml}$ penicillin and $0.03 \% \mathrm{~L}$-glutamine (all obtained from Sigma-Aldrich) and were maintained at $37^{\circ} \mathrm{C}$ with $5 \% \mathrm{CO}_{2}$ in a humidified atmosphere.

MTT assay. The HepG2 cells were seeded in 96-well tissue culture plates (Nunc, Roskilde, Denmark) at a density of $1 \times 10^{4}$ cells/well. Following a $12 \mathrm{~h}$ incubation, the cells were treated with or without DCIVa at a concentration of $0.02,0.04$, $0.06,0.08$ or $0.1 \mu \mathrm{mol} / \mathrm{ml}$, and incubated for 24,48 or $72 \mathrm{~h}$. Following incubation, MTT $(5 \mathrm{mg} / \mathrm{ml}$ in phosphate-buffered saline; PBS) was added (200 $\mu \mathrm{l} /$ well) and incubated for an additional $4 \mathrm{~h}$. DMSO (150 $\mu \mathrm{l} /$ well) was subsequently added to dissolve the formazan product for $15 \mathrm{~min}$. The absorbance at $490 \mathrm{~nm}$ was measured using an ELISA reader (Bio-Tek, Winooski, VT, USA). The experiment was performed five times. The data are representative of three independent experiments. The cell growth inhibition rate was calculated as follows: Cell growth inhibition $(\%)=\mathrm{HepG} 2_{\text {control }}$ - HepG $2_{\text {DCIVa }} /$ HepG $2_{\text {control }}$ X 100.

Observation of morphological changes. The HepG2 cells were seeded into 6-well culture plates at a density of $1 \times 10^{4}$ cells/well. Following a $12 \mathrm{~h}$ incubation, the cells were treated with different concentrations of DCIVa for $24 \mathrm{~h}$. The cellular morphology was observed using an inverted microscope (AE21; Motic, Xiamen, China).

Transmission electron microscopy. The HepG2 cells were seeded into culture flasks at a density of $1 \times 10^{6}$ cells/flask. Following a $12 \mathrm{~h}$ incubation, the cells were treated with or without $0.06 \mu \mathrm{mol} / \mathrm{ml}$ DCIVa for $24 \mathrm{~h}$. The cells were subsequently collected and fixed with fixative. The cell samples were processed into ultra-thin sections in the College of Medicine of Xian Jiaotong University (Xian, China). The ultra-thin sections were examined using a H600 transmission electron microscope (Hitachi, Tokyo Japan).

Hochest 33258 staining. The cells were treated with $0,0.06$ or $0.1 \mu \mathrm{mol} / \mathrm{ml} \mathrm{DCIVa}$ for $24 \mathrm{~h}$ and washed with ice-cold PBS twice prior to fixation with $3 \mathrm{ml}$ ethyl alcohol for $30 \mathrm{~min}$ at room temperature. The fixative was discarded and the cells were washed three times with ice-cold PBS. Hoechst 33258 $(5 \mathrm{mg} / \mathrm{l})$ was added to the cells and incubated for $45 \mathrm{~min}$ in the dark. The cells were washed twice with ice-cold PBS followed by visualization under a Leica AF6000 fluorescence microscope (Leica, Wetzlar, Germany).

Flow cytometric analysis. For cell cycle analysis, following treatment with different concentrations of DCIVa, the cells were harvested and washed with ice-cold PBS. The cells were subsequently fixed in $70 \%$ ethanol and maintained at $4^{\circ} \mathrm{C}$ for at least $12 \mathrm{~h}$. The cell pellets were obtained by centrifugation at $2,000 \mathrm{x}$ g for $10 \mathrm{~min}$ and then stained with a fluorescent probe solution, containing $50 \mu \mathrm{g} / \mathrm{ml} \mathrm{PI}$ and $1 \mathrm{mg} / \mathrm{ml}$ DNase-free RNaseA in PBS on ice in the dark for $30 \mathrm{~min}$. The DNA fluorescence of the PI-stained cells was determined using FACScan flow cytometry (Becton Dickinson, Franklin Lakes, NJ, USA). Analysis of cell apoptosis was performed using an Annexin V/PI apoptosis detection method (Beyotime Institute of Biotechnology, Haimen, China). Briefly, the cells were collected and washed with ice-cold PBS followed by resuspension in binding buffer. The cells were incubated with $10 \mu \mathrm{l}$ Annexin $\mathrm{V}$ stock solution for $30 \mathrm{~min}$ at $4^{\circ} \mathrm{C}$. A total of $5 \mu \mathrm{l}$ PI was subsequently added and the cells were incubated for $5 \mathrm{~min}$. Finally, cells were analyzed by flow cytometry.

Western blot analysis. The HepG2 cells were cultured for $24 \mathrm{~h}$ and the old culture medium was replaced with fresh medium without phenol red and FBS. Following incubation for a further $24 \mathrm{~h}$, the cells were treated with or without DCIVa at the provided concentrations and incubated for $24 \mathrm{~h}$. The adherent and floating cells were harvested and washed with PBS. The cell pellets were obtained by centrifugation at $2,000 \mathrm{x} \mathrm{g}$ for $10 \mathrm{~min}$ and then resuspended in lysis buffer, containing 50 mM HEPES ( $\mathrm{pH} 7.4$ ), 1\% Triton X-100, 2 mM sodium orthovanadate, $100 \mathrm{mM}$ sodium fluoride, $1 \mathrm{mM}$ edetic acid, $1 \mathrm{mM}$ PMSF, $10 \mathrm{mg} / \mathrm{l}$ aprotinin and $10 \mathrm{mg} / \mathrm{l}$ leupeptin, and lysed at $4^{\circ} \mathrm{C}$ for $60 \mathrm{~min}$. Following centrifugation at $13,000 \mathrm{x} \mathrm{g}$ for $15 \mathrm{~min}$, the protein concentration in the supernatant was determined using a Bradford assay (Beyotime Institute of Biotechnology). A total of $20 \mu \mathrm{g}$ protein lysate was separated by electrophoresis on $12 \%$ SDS-polyacrylamide gels (Sangon Biotech Co., Ltd., Shanghai, China) and transferred onto a nitrocellulose membrane (Bio-Rad, Hercules, CA, USA). The membranes were soaked in blocking buffer ( $5 \%$ non-fat milk) at $37^{\circ} \mathrm{C}$ for $1 \mathrm{~h}$. The membranes were incubated with polyclonal rabbit anti-human Bcl-2 antibody (1:500; cat. no. sc-492) monoclonal mouse anti-human Bax antibody (1:1,000; sc-20067)and polyclonal rabbit anti-human $\beta$-actin antibody 
A

C

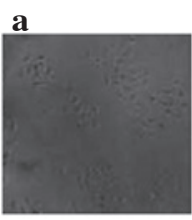

b

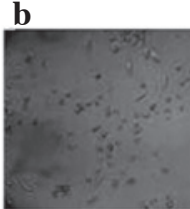

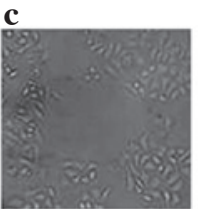

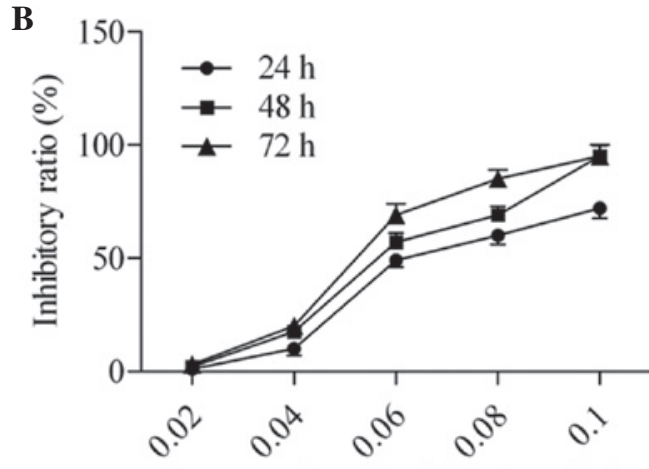

Concentration of DCIVa $(\mu \mathrm{moV} / \mathrm{ml})$
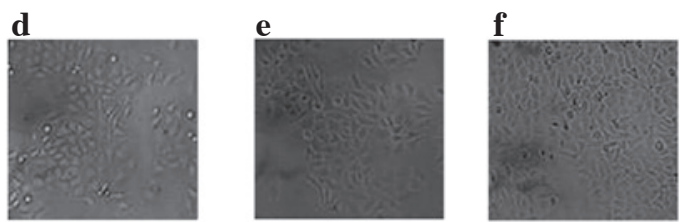

Figure 1. Detection of the cytotoxicity of DCIVa on the HepG2 cells. (A) The chemical structure of DCIVa. (B) The cells were treated with different concentrations of DCIVa $(0.02,0.04,0.06,0.08$ or $0.1 \mu \mathrm{M})$ for 24,48 or $72 \mathrm{~h}$. The inhibitory ratio was determined by an MTT assay. (C) The cellular morphological changes were observed by inverted microscopy following treatment with (Ca) $0.1,(\mathrm{Cb}) 0.08,(\mathrm{Cc}) 0.06,(\mathrm{Cd}) 0.04,(\mathrm{Ce}) 0.02 \mathrm{and}(\mathrm{Cf}) 0 \mu \mathrm{mol} / \mathrm{ml}) . \mathrm{DCIVa}$, deglucose chikusetsusaponin IVa.

A

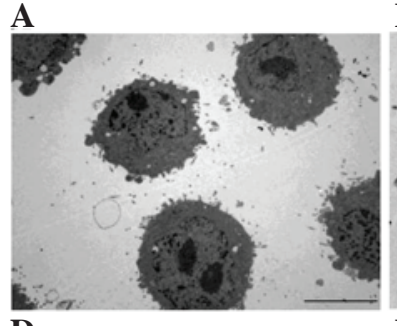

D

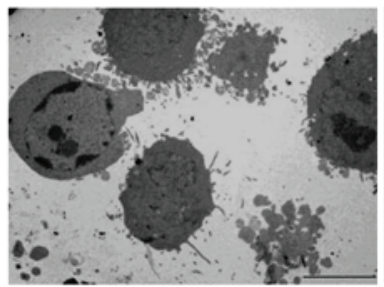

B

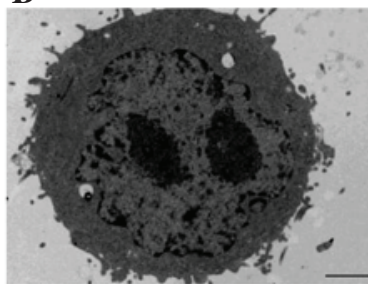

$\mathbf{E}$

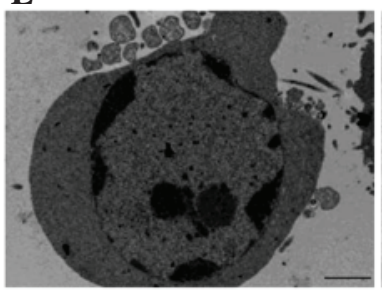

C

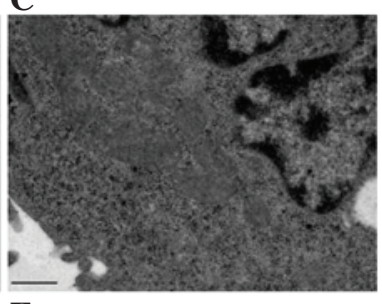

F

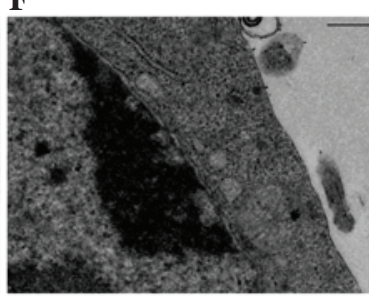

Figure 2. Detection of cell ultrastructure by transmission electron microscopy. (A-C) The control group treated with $0 \mu \mathrm{mol} / \mathrm{ml} \mathrm{DCIVa}$ and (D-F) the experimental cells were treated with $0.06 \mu \mathrm{mol} / \mathrm{ml} \mathrm{DCIVa} \mathrm{(scale} \mathrm{bar} \mathrm{of} \mathrm{A} \mathrm{and} \mathrm{D,} 5 \mu \mathrm{m}$; scale bar of B and E, $2 \mu \mathrm{m}$; scale bar of C and F, $0.5 \mu \mathrm{m}$ ). DCIVa, deglucose chikusetsusaponin IVa.

(1:800; sc-130656)obtained from Santa Cruz Biotechnology (Santa Cruz, CA, USA) at $4^{\circ} \mathrm{C}$ overnight. The membrane was subsequently incubated with anti-rabbit or anti-mouse IgG conjugated with horseradish peroxidase (HRP) for $1 \mathrm{~h}$. The proteins were detected using 3,3'-diaminobenzidine tetrahydrochloride as the HRP substrate.

Statistical analysis. All data are expressed as the mean \pm standard deviation of at least three independent experiments. Statistical comparisons between or among groups were analyzed by two-tailed Student's t-test or one-way analysis of variance, followed by Bonferroni post hoc. Statistical analysis was performed using SPSS version 11.5 (SPSS, Inc., Chicago, IL, USA). $\mathrm{P}<0.05$ was considered to indicate a statistically significant difference.

\section{Results}

DCIVa induces cytotoxicity in a dose- and time-dependent manner. To investigate whether DCIVa (Fig. 1A) was cytotoxic, different doses of DCIVa were added to the HepG2 cells, and the cell growth and viability was measured by an MTT assay. The results demonstrated that DCIVa inhibited cell growth in a dose- and time-dependent manner (Fig. 1B). To further characterize the DCIVa-induced HepG2 cell growth inhibition, the cellular morphology was observed using inverted microscopy. Following treatment with DCIVa, the cells changed to a more round shape and the cell number was reduced in dose-dependent manner, compared with the control group where cells were spindle-shaped and arranged densely (Fig. 1C). 

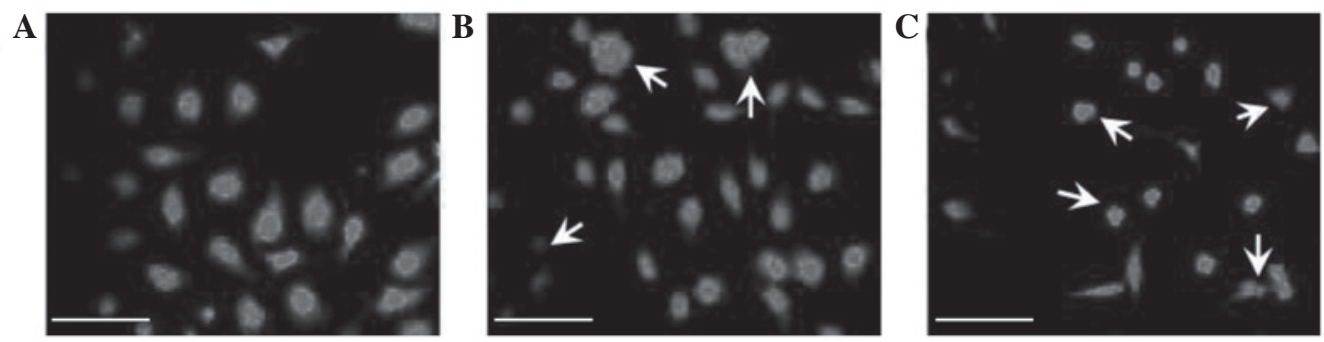

Figure 3. Cell apoptosis was detected by Hoechst staining. The HepG2 cells were treated with different concentrations of DCIVa for $12 \mathrm{~h}$ and subsequently stained with Hoechst 33258. (A) The control group was treated with $0 \mu \mathrm{mol} / \mathrm{ml}$ DCIVa and the experimental group cells were treated with (B) 0.06 or (C) $0.1 \mu \mathrm{mol} / \mathrm{ml}$ DCIVa. The arrow indicates nuclear contraction (scale bar, $50 \mu \mathrm{m}$ ). DCIVa, deglucose chikusetsusaponin IVa.

A

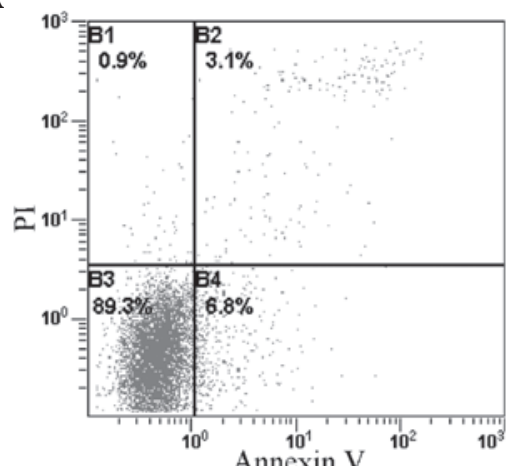

C

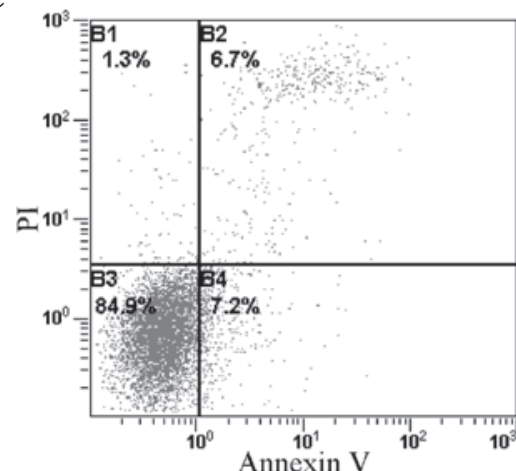

$\mathbf{E}$

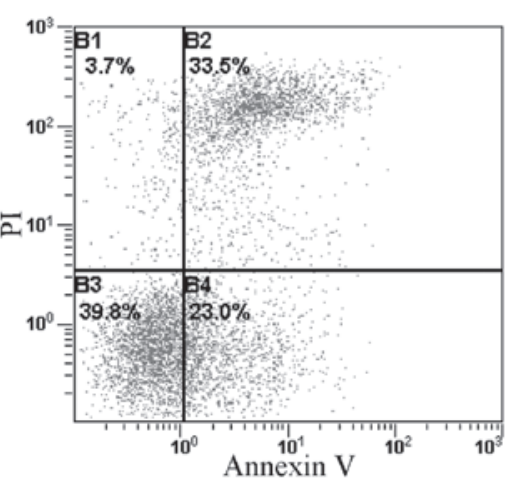

B

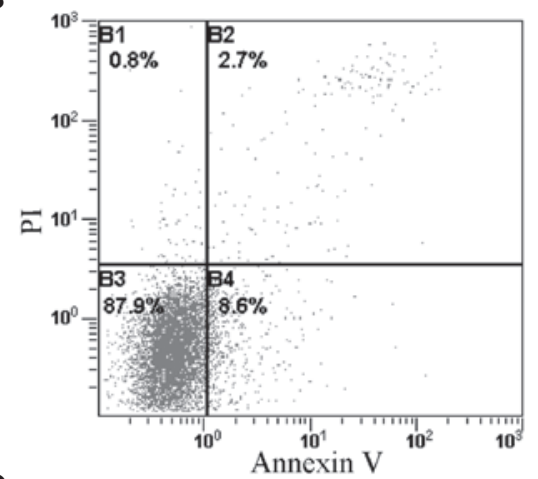

D

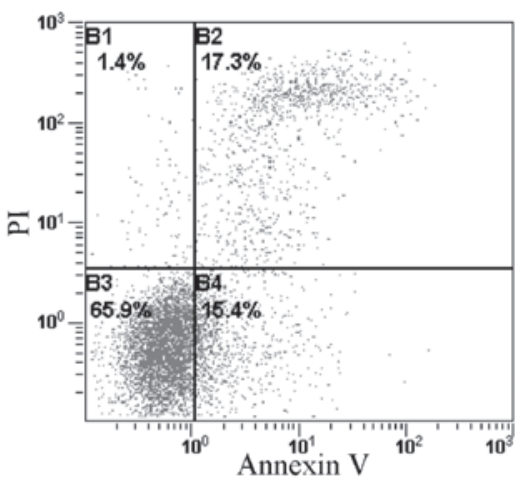

$\mathbf{F}$

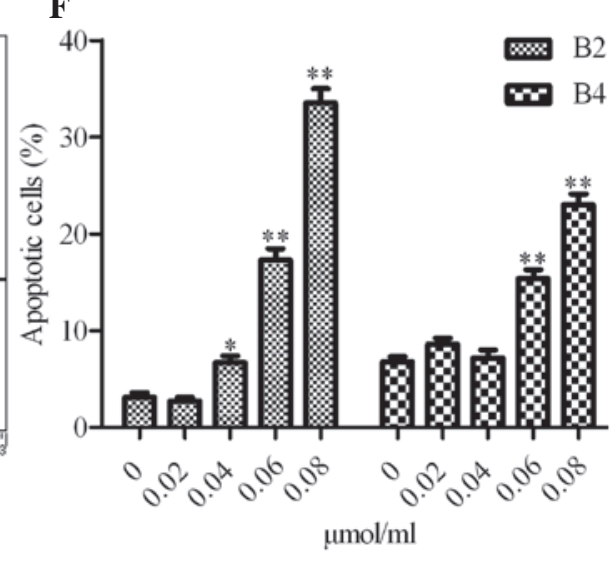

Figure 4. Effect of DCIVa on cell apoptosis, as detected by Annexin V-FITC/PI staining. The HepG2 cells were exposed to (A) 0 , (B) 0.02 (C) 0.04 , (D) 0.06 and (E) $0.08 \mu \mathrm{mol} / \mathrm{ml} \mathrm{DCIVa} \mathrm{for} 24 \mathrm{~h}$ at $37^{\circ} \mathrm{C}$. The cells treated with $0 \mu \mathrm{mol} / \mathrm{ml}$ DCIVa was used as the control group. The cells were harvested and stained by Annexin V-FITC/PI and analyzed by flow cytometry. (F) Representative histograms demonstrating the fractions of cells in the early (B2) and late stage (B4) of apoptosis ("P $<0.05$ and ${ }^{* *} \mathrm{P}<0.01$, compared with the control group). DCIVa, deglucose chikusetsusaponin IVa; FITC, fluorescein isothiocyanate; PI, propidium iodide.

DCIVa induces an apoptotic ultrastructure. To further investigate the effect of DCIVa on the cells, the ultrastructure of the DCIVa-treated HepG2 cells was determined using transmission electron microscopy. As shown in Fig. 2A-C, the control cells exhibited a normal cell phenotype. By contrast, the DCIVa-treated HepG2 cells demonstrated typical apoptotic 
A

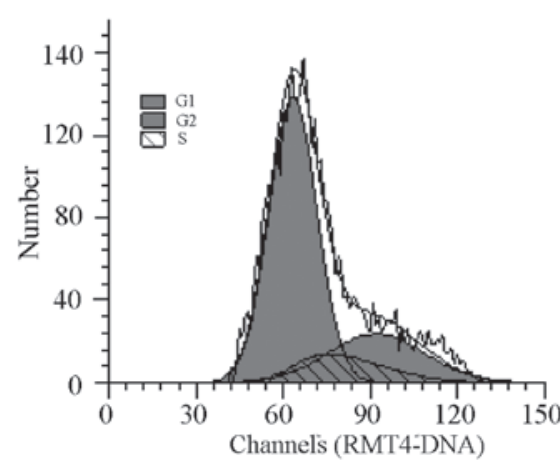

B

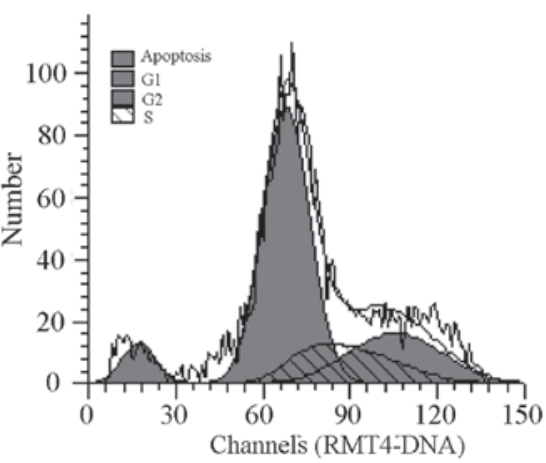

D

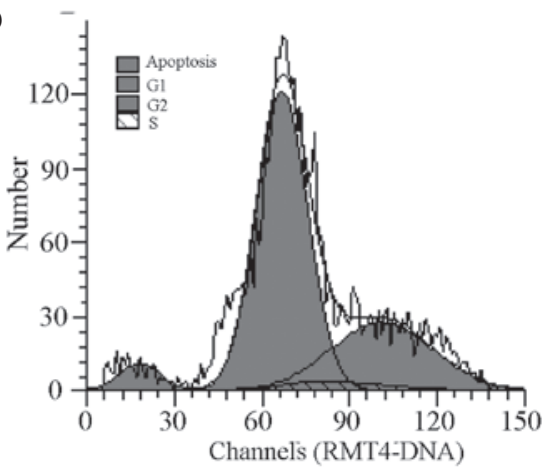

F

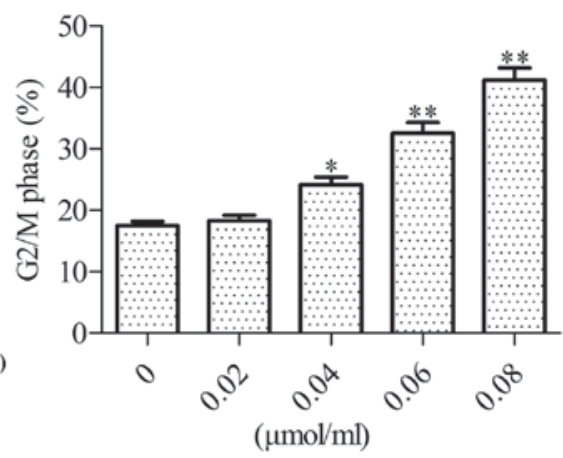

Figure 5. Effect of DCIVa on the cell cycle. The HepG2 cells were treated with (A) 0 , (B) 0.02 (C) 0.04 , (D) 0.06 and (E) $0.08 \mu \mathrm{mol} / \mathrm{ml} \mathrm{DCIVa}$ for $24 \mathrm{~h}$ and were analyzed by DNA flow cytometry. The cells treated with $0 \mu \mathrm{mol} / \mathrm{ml}$ DCIVa were used as the control group. (F) Representative histograms for cell cycle G2/M phase distribution in the HepG2 cells ( $\mathrm{P}<0.05$ and ${ }^{* *} \mathrm{P}<0.01$, compared with the control group). DCIVa, deglucose chikusetsusaponin IVa.

features, including chromatin condensation, margination at the nuclear periphery and the formation of apoptotic bodies (Fig. 2D-F).

DCIVa triggers nuclear contraction and fragmentation. The effect of DCIVa on the nucleus was assessed by Hoechst 33258 staining. The results revealed that the HepG2 cell nucleus was condensed and fragmented upon treatment with 0.06 (Fig. 3B) and $0.1 \mu \mathrm{mol} / \mathrm{ml}$ DCIVa (Fig. 3C) treatment, compared with the control, further confirming the pro-apoptotic effect of DCIVa.

DCIVa induces cell apoptosis. To further determine the effect of DCIVa on cell apoptosis, cell apoptosis was determined using an Annexin V-fluorescein isothiocyanate/PI assay. Following treatment with different concentrations of DCIVa, the number of cells in different stages of the cell cycle were measured by flow cytometry. As compared with
DCIVa $(\mu \mathrm{mol} / \mathrm{ml})$

\begin{tabular}{|c|c|c|c|c|}
\hline 0 & 0.02 & 0.04 & 0.06 & \multirow[t]{2}{*}{.08} \\
\hline & & - & & \\
\hline- & 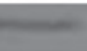 & $=$ & - & $=$ \\
\hline
\end{tabular}

Figure 6. Effect of DCIVa on the expression levels of apoptosis-associated proteins. The HepG2 cells were treated with $0,0.02,0.04,0.06$ or $0.08 \mu \mathrm{mol} / \mathrm{ml}$ DCIVa and the total protein extracts were prepared following treatment for $24 \mathrm{~h}$. The protein expression levels were assessed by western blotting with antibodies against $\mathrm{Bax}$ and $\mathrm{Bcl}-2 . \beta$-actin was used as a loading control. The western blot is representative of three independent experiments. DCIVa, deglucose chikusetsusaponin IVa.

control cells (Fig. 4A), 0.02 (Fig. 4B) and $0.04 \mu \mathrm{mol} / \mathrm{ml}$ (Fig. 4C) DCIVa had no obvious effect on the number of 
early stage apoptotic cells. Treatment with 0.06 (Fig. 4D) and $0.08 \mu \mathrm{mol} / \mathrm{ml}$ (Fig. 4E) DCIVa significantly increased the number of early stage apoptotic cells by 15.4 and $23.0 \%$ (Fig. 4F), respectively, compared with the control cells. Furthermore, 0.04 (Fig. 4C), 0.06 (Fig. 4D) and $0.08 \mu \mathrm{mol} / \mathrm{ml}$ (Fig. 4E) DCIVa markedly increased the number of late-stage apoptotic cells by $6.7,17.3$ and $33.5 \%$ (Fig. 4F), respectively. However, $0.02 \mu \mathrm{mol} / \mathrm{ml}$ (Fig. 4B) DCIVa caused no significant effect on the number of late stage apoptotic cells compared with the control group.

DCIVa induces cell-cycle arrest. Next, the effect of DCIVa on cell cycle was determined. Flow cytometric analysis demonstrated that the HepG2 cell cycles markedly changed following treatment with different concentrations of DCIVa. The results revealed that the number of cells in the $\mathrm{G} 2 / \mathrm{M}$ phase were significantly increased from 17.32 (Fig. 5A) or 18.52 (Fig. 5B) to 23.08 (Fig. 5C), 31.92 (Fig. 5D) and 40.52\% (Fig. 5E) upon treatment with $0,0.02,0.04,0.06$ and $0.08 \mu \mathrm{mol} / \mathrm{ml} \mathrm{DCIVa}$, respectively (Fig. 5F).

DCIVa activates pro-apoptotic pathways. To determine the underlying mechanism of DCIVa-induced cell apoptosis, western blot analysis was performed to determine the expression levels of Bax and $\mathrm{Bcl}-2$. The result demonstrated that the protein expression of $\mathrm{Bcl}-2$ was decreased, whereas the expression of Bax was increased by different concentrations of DCIVa, in a dose-dependent manner (Fig. 6).

\section{Discussion}

DCIVa, an active constituent extracted from Rhizoma Panacis Majoris, has been demonstrated to have exert pharmacological activities, including an anti-arrhythmic effect (13) and a protective effect against hypoxia/reoxygenation-induced injury on myocardial cells (14). However, the antitumor effect of DCIVa remains to be elucidated. In the present study, evidence suggested for the first time, to the best of our knowledge, that DCIVa exerted an antitumor effect by inducing cell apoptosis and cell cycle arrest in the HepG2 cells. Therefore, DCIVa may be a promising compound for the development of anticancer drugs.

The cytotoxic activity of oleanane triterpenoids has been reported in numerous previous studies. Zhang et al (16) demonstrated that oleanane-type triterpene saponins isolated from Albizia inundata exhibited cytotoxicity against melanoma cells and human head and neck squamous cells. The oleanane synthetic triterpenoid, CDDO-Me, revealed antitumorigenic activity against prostate cancer by inactivation of Akt and nuclear factor- $\kappa \mathrm{B}(15,17)$. Group B oleanane triterpenoid extract, containing Soy saponins I and III from Soy Flou induced apoptosis in the HepG2 cells (18). The present study identified and characterized DCIVa, a type of oleanane triterpenoids, and revealed that this exhibited an antitumor effect in HepG2 cells. Using an MTT assay, it was revealed that DCIVa inhibited HepG2 cell growth in a dose-dependent manner. The alteration of cell morphology was essential for the medicinal mechanism, which triggers drug-mediated apoptosis in the cells. In the present study, it was demonstrated that DCIVa caused cell atrophy and induced typical apoptotic features, including chromatin condensation, margination at the nuclear periphery, apoptotic bodies formation and nuclear condensation and fragmentation. These findings suggested that DCIVa induced apoptosis in the HepG2 cells. The results of flow cytometric analysis demonstrated that DCIVa induced an increase in early stage apoptotic cells and late stage apoptotic cells, further confirming that DCIVa induced cell apoptosis.

Alteration in the $\mathrm{Bax} / \mathrm{Bcl}-2$ ratio has been suggested to be crucial for the activation of the mitochondrial apoptotic pathway $(19,20)$. Various anticancer drugs have been demonstrated to induce cell apoptosis through regulating $\mathrm{Bax} / \mathrm{Bcl}-2$. Boldine was revealed to exert cytotoxic and chemotherapeutic properties by downregulating the expression of Bcl-2 and simultaneously promoting the expression of Bax, therefore leading to cell apoptosis in breast cancer cells (21). Rice bran phytic acid was reported to induce apoptosis via regulation of $\mathrm{Bcl}-2 / \mathrm{Bax}$ in HepG2 cells (22) and Persea declinata (B1.) Kosterm bark methanolic crude extract induced cell apoptosis through upregulation of Bax and downregulation of Bcl-1 in human breast cancer cells (23). In the present study, it was further demonstrated that treatment with DCIVa activated the mitochondrial apoptotic pathway. The data revealed that the pro-apoptotic protein, Bax, was induced by DCIVa, whereas the anti-apoptotic protein, Bcl-2, was inhibited by DCIVa. A novel oleanane triterpenoid, meth yl-25-hydroxy-3-oxoolean-12-en-28-oate, has been demonstrated to induce apoptosis by regulating the expression of Bax and Bcl-2 (24). This data suggested that DCIVa, as a type of oleanane triterpenoid, exerted cytotoxicity through the induction of cell apoptosis, by mediating the expression levels of Bax and Bcl-2.

In addition, the present study demonstrated that DCIVa induced a cell cycle arrest in the $\mathrm{G} 2 / \mathrm{M}$ phase. Cell cycle checkpoints are critical events for cell proliferation, which guarantee the integrity of the DNA and proper timing of cell division. If the DNA is damaged, the cell cycle is inhibited at the G2/M phase to initiate the repair mechanism for DNA (25). However, excessive DNA damage results in cell apoptosis. Using flow cytometric analysis, it was demonstrated that DCIVa induced G2/M cell cycle arrest in a dose-dependent manner. However, various genes are involved in the regulation of the G2/M checkpoint and the effect of DCIVa on the G2/M checkpoint regulatory proteins and the underlying mechanism remain to be elucidated.

In conclusion, the present study provided evidence that DCIVa exhibits a potent cytotoxic effect on HepG2 cells through the induction of cell apoptosis and cell cycle arrest. These findings contributed to the development of DCIVa as a potential anticancer agent. However, further investigation into the antitumor effects of DCIVa in vitro and in vivo are required.

\section{Acknowledgements}

The present study was supported by the National Natural Sciences Foundation of China (grant nos. 81102805 and 81373978) and the Innovation Program on Science and Technology Project of Shaanxi Province (grant nos. 2011KTCQ03-02 and 2013KTCQ03-14). 


\section{References}

1. Xu Q, Bauer R, Hendry BM, Fan TP, Zhao Z, Duez P, Simmonds MS, Witt CM, Lu A, Robinson N, et al: The quest for modernisation of traditional Chinese medicine. BMC Complement Altern Med 13: 132, 2013.

2. Wang L, Li Y, Li J, Zhang M, Xu L, Yuan W, Wang G and Hopewell S: Quality of reporting of trial abstracts needs to be improved: Using the CONSORT for abstracts to assess the four leading Chinese medical journals of traditional Chinese medicine. Trials 11: 75, 2010.

3. Zhao R, Zhao Y, Li D, Wang J and Zeng Y: Research progress of panax japonicus. Modern Chinese Medicine 10: 3-6, 2008.

4. Zou K, Liu Z, Zhu S, Cai S and Komatsu K: Research of ginsenosides in kou zi qi using HPLC-MS-MS. Yao Xue Xue Bao 39: 385-388, 2004 (In Chinese).

5. Wang DQ, Feng BS, Wang XB, Yang CR and Zhou J: Further study on dammarane saponins of leaves of Panax japonicus var. Major collected in Quinling Mountains China. Yao Xue Xue Bao 24: 633-636, 1989 (In Chinese).

6. Zhu XH, Hou WJ and Li CD: Study of effect of Panax Japonicus Saponin on spleen lymphocyte proliferous response. Academic Journal of Kunming Medical College 15: 65-67, 1994 (In Chinese).

7. He H, Shi M, Chen T, Lu X, Qin N and Chen S: Anti-inflammatory and analgesic effect of water extractive of Panacis Majoris Rhizoma in mice. Acta Academiae Medicinae Militaris Tertiae 20: 20, 2010

8. Mengqiong S, Haibo H, Ningling Q and Shuwei C: Effect of pretreatment with water extract from Rhizoma Panacis majoris on cerebral ischemia-reperfusion injury in mice. Acta Academiae Medicinae Militaris Tertiae 3: 023, 2011.

9. Chen T, Gong Z and Fu Y: Rhizoma Panacis majori reduces toxicity of chemotherapy in S180-bearing mice. Zhong Xi Yi Jie He Xue Bao 6: 1255-1258, 2008 (In Chinese).

10. Chen $\mathrm{C}, \mathrm{Wu} \mathrm{W}, \mathrm{Xu} \mathrm{X}$, Zhang L, Liu Y and Wang K: Chain conformation and anti-tumor activity of derivatives of polysaccharide from Rhizoma Panacis Japonici. Carbohydr Polym 105: 308-316, 2014

11. Huang Z, Ren H, Duan X and Zhang L: Chain conformation and bioactivity of water-soluble polysaccharide extracted from Rhizoma Panacis Japonici. Biopolymers 93: 383-390, 2010.

12. Song X, Li L, Yang G and Cai B: HPLC determination of chikusetsusaponin IVa in Rhizoma Panacis Majoris from different producing areas. Zhongguo Zhong Yao Za Zhi 35: 885-887, 2010 (In Chinese).
13. Sun GB, Xu HB, Wen FC, Ding T and Sun XB: Study of anti-experimental arrhythmia effect of deglucose Chikusetsu Saponin IVa. Chin J Pharmacol Toxicol 20: 377-380, 2006 (In Chinese).

14. Sun GB, Xu HB, Wen FC, Zhang W, Ding T and Sun XB: Protective Effects of Deglucose Chikusetsu Saponin IVa on Cultured Myocardial Cells Subjected to Anoxia Reoxygenation Injury. Chin J Pharmacol Toxicol 19: 424-427, 2005 (In Chinese)

15. Liu Y, Gao X, Deeb D and Gautam SC: Oleanane triterpenoid CDDO-Me inhibits Akt activity without affecting PDK1 kinase or PP2A phosphatase activity in cancer cells. Biochem Biophys Res Commun 417: 570-575, 2012.

16. Zhang H, Samadi AK, Rao KV, Cohen MS and Timmermann BN: Cytotoxic oleanane-type saponins from Albizia inundata. J Nat Prod 74: 477-482, 2011.

17. Gao X, Deeb D, Liu Y, Arbab AS, Divine GW, Dulchavsky SA and Gautam SC: Prevention of prostate cancer with oleanane synthetic triterpenoid CDDO-Me in the TRAMP mouse model of prostate cancer. Cancers (Basel) 3: 3353-3369, 2011.

18. Zhang W and Popovich DG: Group B oleanane triterpenoid extract containing soyasaponins I and III from soy flour induces apoptosis in Hep-G2 cells. J Agric Food Chem 58: 5315-5319, 2010.

19. Antonsson B and Martinou JC: The Bcl-2 protein family. Exp Cell Res 256: 50-57, 2000.

20. Reed JC: Double identity for proteins of the Bcl-2 family. Nature 387: 773-776, 1997.

21. Paydar M, Kamalidehghan B, Wong YL, Wong WF, Looi CY and Mustafa MR: Evaluation of cytotoxic and chemotherapeutic properties of boldine in breast cancer using in vitro and in vivo models. Drug Des Devel Ther 8: 719-733, 2014.

22. Al-Fatlawi AA, Irshad M, Zafaryab M, Rizvi MM and Ahmad A: Rice bran phytic acid induced apoptosis through regulation of Bcl-2/Bax and p53 genes in HepG2 human hepatocellular carcinoma cells. Asian Pac J Cancer Prev 15: 3731-3736, 2014.

23. Narrima P, Paydar M, Looi CY, Wong YL, Taha H, Wong WF, Ali Mohd M and Hadi AH: Persea declinata (B1.) Kosterm bark crude extract induces apoptosis in MCF-7 cells via G0/G1 cell cycle arrest, Bcl-2/Bax/Bcl-xl signaling pathways and ROS generation. Evid Based Complement Alternat Med 2014: 248103, 2014.

24. Bishayee A, Mandal A, Thoppil RJ, Darvesh AS and Bhatia D: Chemopreventive effect of a novel oleanane triterpenoid in a chemically induced rodent model of breast cancer. Int $\mathrm{J}$ Cancer 133: 1054-1063, 2013.

25. Hartwell LH and Weinert TA: Checkpoints: controls that ensure the order of cell cycle events. Science 246: 629-634, 1989. 